\title{
Dinámica del empleo en sectores intensivos en uso del conocimiento en la Megalópolis del Valle de México, 2014-2018
}

\section{Dynamics of employment in sectors of intensive use of knowledge in the Megalopolis of the Valley of Mexico, 2014-2018}

\author{
Iván Vilchis-Mata' ${ }^{1}$, Carlos Garrocho-Rangel ${ }^{2}$ (c) \\ y Tania Chávez-Soto ${ }^{3}$ (1)
}

\begin{abstract}
RESUMEN
El capital humano calificado es clave para el progreso de las ciudades. El objetivo del trabajo es contestar las preguntas ¿cuánto, dónde, en qué sectores, cuándo y por qué cambió el empleo en los sectores intensivos en uso de conocimiento (SIUCs) en la Megalópolis de la Zona Metropolitana del Valle de México, sus principales ciudades y en sus Municipios y Alcaldías? Esta Megalópolis es el principal motor del desarrollo nacional. Es necesario entender la dinámica de su empleo SIUCs, para aprovechar mejor sus efectos positivos y prevenir los negativos. El periodo de análisis es 2014-2018: cubre el último tramo del Tratado de Libre Comercio entre México, Estados Unidos y Canadá, antes de las modificaciones de 2019, y casi todo un periodo del gobierno federal. Se utiliza el método Cambio-Participación Espacial (ACPE). Se identifican territorios ascendentes y otros en dramático declive. Los argumentos conceptuales del ACPE se traducen en causas del cambio del empleo, se miden los cambios según su causa a tres escalas espaciales (megalopolitana, metropolitana y microespacios), y se vinculan esos cambios con empresas y productos específicos, en territorios y sectores concretos.
\end{abstract}

Palabras clave: Capital humano calificado, sectores de uso intensivo del conocimiento, análisis Shift-Share Espacial.

\section{ABSTRACT}

Qualified human capital is key to the progress of cities. The objective of this work is to answer the following questions: how much, where, in which sectors, when, and why did employment change in knowledge-intensive sectors (KIS) in the Megalopolitan Region of the Valley of Mexico, its main cities, and in its municipalities? This Megalopolis is the main engine of national development. It is necessary to understand the dynamics of the Megalopolitan KIS employment, to take advantage of its positive effects, and prevent negative ones. The analysis period is 2014-2018: it covers the last section of the Free Trade Agreement between Mexico, the United States, and Canada, before the modifications 


\begin{abstract}
negotiated in 2019, and almost a whole period of the federal government. The method is Spatial-Shift Share Analysis (SSS). It was possible to identify ascending territories, and others in dramatic decline. We translate the SSS concepts into causes of employment change, measure the changes at three spatial scales (megalopolitan, metropolitan and micro-spaces), and linked the changes to specific companies and products, in particular territories and sectors.
\end{abstract}

Keywords: Qualified human capital, knowledge intensive sectors, Spatial Shift-Share analysis

El desarrollo de las megalópolis (en Europa: 'polycentric urban regions') se asocia a la interacción de numerosos factores que operan a diversas escalas geográficas (Meijers et al., 2018). Algunos autores exploran la influencia de sus estructuras funcional y espacial (e.g. flujos interurbanos, jerarquía de ciudades: Glaeser et al., 2016). Otros se enfocan a factores demográficos que redistribuyen en el territorio empresas, recursos humanos, valores, actitudes (e.g. migraciones de personas y firmas: Arribas-Bel \& Sanz-Gracia, 2014). Algunos más analizan elementos contextuales intrínsecos (e.g. clima, recursos naturales, historia socioeconómica: Van Meeteren et al., 2016), institucionales (e.g. coordinación gubernamental y empresarial: Sweet et al., 2017), legales (e.g. leyes y regulaciones: Sinclair-Smith, 2015), programas de incentivos y desincentivos (e.g. políticas públicas, planes: Li \& Monzur, 2018), entre otros. La importancia de estos factores no es clara y al momento no es posible una aproximación holística (Dadashpoor \& Malekzadeh, 2020).

La literatura reciente privilegia la relación entre el desarrollo de las megalópolis y su desempeño económico (Wang \& Niu, 2019). Específicamente, la influencia de factores que reconfiguran el funcionamiento espacial de sus economías: infraestructura, productividad, competitividad, capital humano calificado (Kwon \& Seo, 2018). En la economía del conocimiento e innovación, el capital humano tiene una importancia sobresaliente (Fritsch \& Wyrwich, 2021; OECD, 2019).

Estudios que exploran el desarrollo de la megalópolis y el capital humano calificado (aquel que se inserta en sectores que hacen uso intensivo del conocimiento, en adelante SIUCs) se orientan principalmente a Europa Occidental y China. El tema no ha sido explorado a fondo en Latinoamérica (Dadashpoor \& Malekzadeh, 2020: 294). Este texto contribuye a llenar este hueco en la literatura latinoamericana.

Su objetivo es explicar la dinámica del empleo SIUCs en la Megalópolis de la Zona Metropolitana del Valle de México (en adelante: Megalópolis), sus principales ciudades y en sus Municipios y Alcaldías (microespacios). Las preguntas de investigación son: ¿cuánto, dónde, en qué sectores, cuándo y por qué cambió el empleo SIUCs en el sistema megalopolitano y en sus ciudades claves?

Las preguntas son relevantes. El capital humano SIUCs es fundamental para el desarrollo de la Megalópolis, que intenta insertarse en la economía global del conocimiento (Ordóñez \& García, 2019) 4 . La Megalópolis es la región urbana más importante de México. Registra 48.1 millones de habitantes (37.8 por ciento del total nacional: Conapo-Inegi, 2018) y genera casi un tercio del PIB del país (CITIBANAMEX, 2017). Al ser motor principal del desarrollo nacional, sus conductores

En México, el empleo SIUCs crece cincuenta por ciento más lento que el empleo total, se concentra en las ciudades de mayor tamaño (CITIBANAMEX, 2017; Sobrino, 2016) y se asocia positivamente al PIB per cápita (Garrocho, 2013). 
(públicos y privados) requieren entender la dinámica del empleo SIUCs en espacio, sectores y tiempo, para aprovechar sus efectos positivos y prevenir los negativos (inflación, segregación, desigualdad, gentrificación: O'Sullivan, 2018; Storper, 2013).

En lo que sigue el texto se divide en cinco secciones. La primera examina los temas básicos del marco conceptual: cómo se explica el desempeño económico de las megalópolis y cuál es la importancia del empleo SIUCs. La segunda sección es instrumental, presenta la zona de estudio, los SIUCs que se analizan, las fuentes de información y el software utilizado. En la tercera sección se detalla la metodología, que permite considerar el desempeño económico de la Megalópolis, su estructura espacial y su integración funcional a diversas escalas geográficas. En la cuarta sección se aplica el método y analizan los resultados. Finalmente, en la última sección se discuten y sintetizan las conclusiones y aportaciones del trabajo.

\section{Desempeño económico de las megalópolis: economías de integración}

La concentración espacial de población y actividades genera ventajas que elevan el desempeño económico de firmas y ciudades, llamadas economías de aglomeración (Duranton \& Puga 2004). Se generan por la complementariedad entre firmas y por ahorros en sus costos de producción al compartir factores productivos claves: mercado de trabajo, flujos de conocimiento e información, servicios especializados, infraestructura colectiva, amenidades, entre otros (Burger \& Meijers 2016).

Si las ventajas de aglomeración sirven a firmas similares, se conocen como economías de localización: ejemplos clásicos son Hollywood, Silicon Valley, Wall Street, que se benefician de la concentración espacial de conocimiento y mercados laborales especializados. Si las ventajas se derivan de las características de la ciudad en su conjunto y favorecen a diversas industrias y sectores de la economía, reciben el nombre de economías de urbanización (Johansson \& Quigley 2004).

La generación de economías de urbanización se ha asociado positivamente al tamaño y densidad de las ciudades (Combes \& Gobillon, 2015), aunque esto no significa que todas las megalópolis reporten ventajas que compensen sus costos (e.g. alto costo de la vivienda y el suelo, costos de congestión) (Camagni et al., 2017). Varios autores proponen que la integración económica de las ciudades es más importante que su densidad y magnitud (Meijers et al., 2016), lo que implica que existen economías generadas por "externalidades de las redes de ciudades" (Burger \& Meijers 2016) $)^{5}$, que aquí llamamos economias de integración. Glaeser et al. (2016) proponen, en términos teóricos, que una red altamente integrada de ciudades medias puede generar iguales o mayores economías (ventajas) que una gran ciudad, pero no existe evidencia empírica que lo demuestre (Meijers et al., 2018).

La interacción al interior de las ciudades y entre ciudades, es fundamental para producir economías de localización, urbanización e integración (Duranton \& Puga 2004). Especialmente en las 
megalópolis, donde la integración puede sustituir/complementar las ventajas de la proximidad (o costos de transporte) (Johansson \& Quigley 2004). ${ }^{6}$ El corolario es lógico: las ciudades más integradas a la red urbana de la megalópolis pueden generar mayores ventajas (economías de aglomeración y economías de integración) y mejor desempeño económico, que las ciudades menos integradas (Meijers et al., 2018).

\section{Empleo en SIUCs}

La integración interurbana es importante para el desarrollo de las megalópolis, pero no es lo único. En el siglo XXI el desempeño económico depende cada vez más del conocimiento e innovación (Fritsch \& Wyrwich, 2021). Estos fenómenos tienden a concentrarse en el territorio (Kaufmann, 2020) y se vinculan a la disponibilidad de capital humano calificado (Baily \& Montalbano, 2018; Malizia et al., 2020). Algunos territorios aglomeran factores claves para detonar y sostener procesos de innovación, incrementan su productividad, avanzan en la sociedad del conocimiento; otros no, y se rezagan (Baily \& Montalbano, 2018). Las razones no se conocen con certeza (Malizia et al., 2020), por lo que no hay teoría que explique holísticamente el desarrollo diferenciado de las ciudades (Shearmur, 2016).

Lo que existe, son diversos enfoques sobre factores claves que favorecen concentraciones de innovación. Para este trabajo destacan el de la nueva geografía económica (Hassink \& Gong, 2019) y el de la geografía de la producción (Storper, 2013). Lo notable, es que todos los enfoques coinciden en la importancia de contar con recursos humanos calificados, capaces de insertarse en SIUCs (Katz \& Wagner, 2014; OECD, 2019). Esto también aplica para ciudades latinoamericanas (México: Sobrino, 2016; Chile: Maripani \& Adio, 2019).

Los SIUCs son aquellos que requieren capital humano calificado (Almejo \& Campos, 2013). No sólo juegan un papel trascendente en la innovación, productividad y transmisión de información: por cada empleo SIUCs se generan alrededor de cinco empleos en sectores menos calificados (Moretti, 2012).

La ciudad es un referente de innovación y productividad, por su gran capacidad de generar, atraer y acumular capital humano calificado (Storper, 2013). Al concentrar una mayor cantidad de residentes altamente competitivos y con salarios elevados (en términos relativos), las áreas urbanas se convierten en nodos de desarrollo y crecimiento. En el tablero territorial se juega un ajedrez socioeconómico con partidas simultáneas entre ciudades (Glaeser, 2011): unas ganan (San Francisco, Seattle, Querétaro), otras pierden (Baltimore, Tampico, Poza Rica) (Garrocho, 2013; Davis \& Dingel, 2020).

Las explicaciones de este desempeño urbano diferenciado son diversas, parciales, a menudo singulares: calidad de las instituciones, eficiencia y equidad social (Diamond, 2018), políticas y ambiente urbano, cambios tecnológicos disruptivos, amenidades (Glaeser, 2011), presencia de

Los costos de transporte no se refieren sólo al traslado de bienes tangibles, sino al costo de proveer servicios en el lugar o al de intercambiar información intangible que sólo puede transmitirse "cara a cara" (Maskell, 2001). 
personal altamente calificado, interacción social local, información flotando en el entorno (Moretti, 2012; Storper, 2013), economías de aglomeración, ambiente innovador, participación en la economía global (Porter, 2003), economías de escala, ventajas competitivas, incluso el azar (Krugman, 1991). No existe un marco teórico completo que explique por qué unas ciudades avanzan más que otras.

Las ciudades ganadoras aprovechan economías de aglomeración-integración y crean ecosistemas que innovan y/o aprovechan mejor las innovaciones. Elevan su productividad, reproducen externalidades positivas en lo económico, lo social, lo ambiental (Gleaser, 2011; Moretti, 2012). Toda la población se beneficia, incluso la de bajo nivel de calificación: hay más opciones de empleo, más y mejor información sobre oportunidades, aumenta la productividad, los salarios, el bienestar (Gontero \& Albornoz, 2019).

Esta concentración territorial del capital humano es, en muchos casos, circular y acumulativa en el largo plazo (Vicente, 2018). No obstante, existen ejemplos notables de regiones y ciudades que luego de alcanzar éxito global, enfrentaron decadencia acelerada: por macro procesos globales de relocalización económica, cambios tecnológicos disruptivos, pérdida de competitividad empresarial (e.g. la industria automotriz en Detroit: LeDuff, 2014).

No todos los efectos del empleo SIUCs son benéficos para la ciudad (Storper, 2013). La co-localización de empleos poco calificados y SIUCs puede conducir a discriminación salarial, división entre una población que consume y otra que atiende, polarización, segregación, desigualdad, inflación (notablemente en suelo y vivienda), gentrificación (Rodríguez-Pose \& Storper, 2020).

Para aprovechar mejor los efectos positivos del empleo SIUCs y prevenir los negativos, el primer paso es entender su dinámica en espacio, sector y tiempo. Esto es lo que se propone lograr en este trabajo, para el caso de la Megalópolis.

\section{Zona de estudio y aspectos instrumentales}

La Megalópolis se localiza en el centro de México, sobre ocho entidades federativas (Figura $\left.N^{\circ} 1\right)^{7}$. Está integrada por 585 municipios y 16 alcaldías (equivalentes a municipios en la CDMX). En total suma 601 unidades político-administrativas con gobiernos autónomos (microespacios) (SEDATU et al., 2018).

Su población total en 2020 se estima en 48.1 millones. Las ciudades aquí consideradas, son las zonas metropolitanas (en adelante ZM) más pobladas de la Megalópolis, aquellas que cuentan con una población cercana o mayor a un millón de habitantes: la del Valle de México, Puebla-Tlaxcala, Toluca, Querétaro, y Cuernavaca (Cuadro N01). Este umbral de relevancia urbana se ha utilizado en trabajos recientes sobre ciudades mexicanas (Garrocho y Sobrino, 2018). En 2020 estas cinco ZM concentraban alrededor de 62 por ciento de la población total de la Megalópolis y en 2018, 78 por ciento de su empleo SIUCs (Cuadro $\mathrm{N}^{\circ} 2$ ). 
El análisis comprende el periodo 2014-2018. Cubre el último tramo del Tratado de Libre Comercio entre México, Estados Unidos y Canadá, antes de las modificaciones de 2019. También abarca casi todo un sexenio federal. Para estos años existe información con la desagregación espacial y sectorial requerida. El periodo es suficiente para apreciar cambios estructurales regionales y locales (Rendón et al., 2019).

Los SIUCs considerados se han justificado ampliamente en trabajos recientes para ciudades mexicanas (Almejo \& Campos, 2013; Garrocho, 2013; Shearmur et al., 2015) (ver Cuadro No3). La información del empleo por SIUCs, Grupos y Subsectores se estimó con el Directorio Estadístico Nacional de Unidades Económicas (DENUE-INEGI 2014; 2018).

Figura $\mathrm{N}^{\circ} 1$.

Zona de estudio

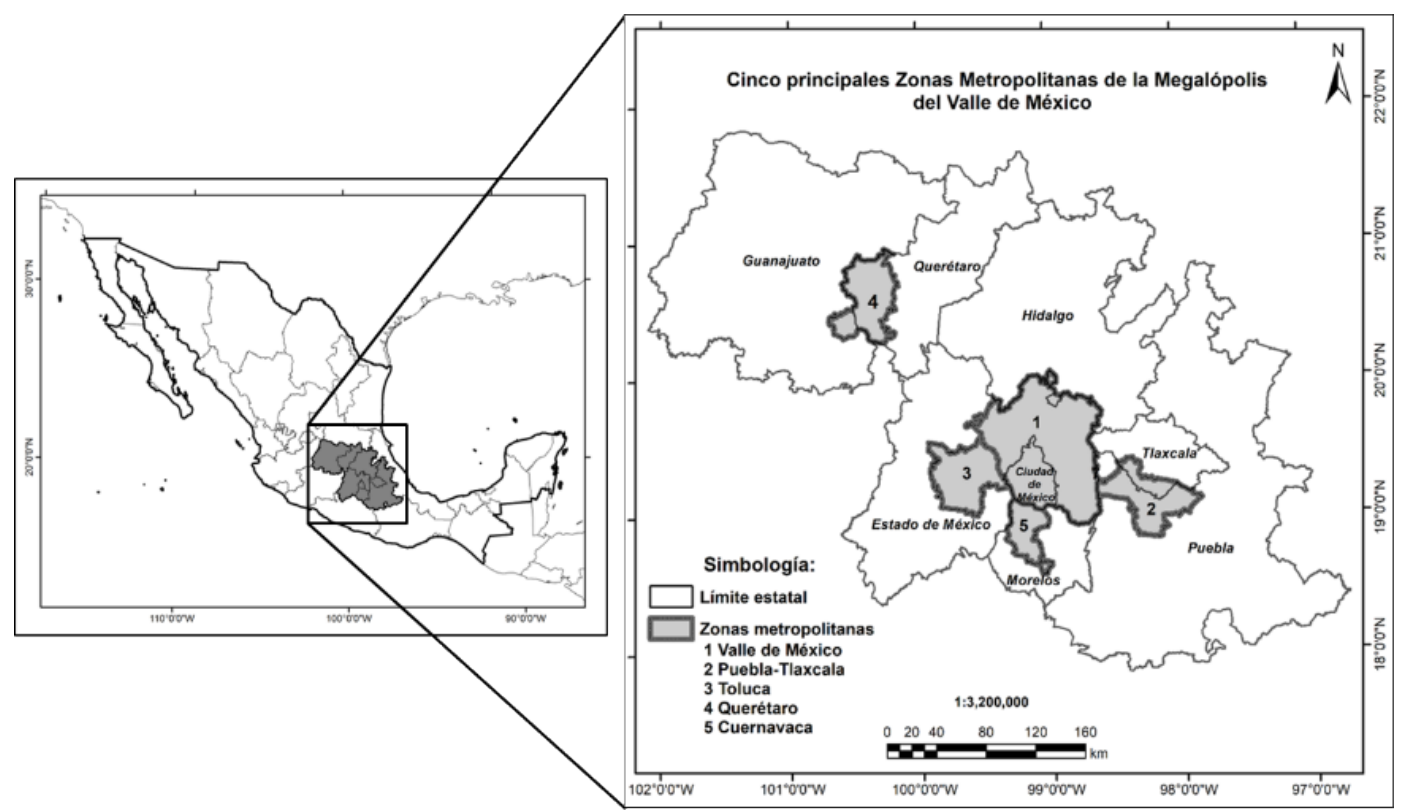

Fuente: Elaboración propia. 
Cuadro $\mathrm{N}^{\circ} 1$.

Principales zonas metropolitanas de la Megalópolis del Valle de México, 2014-2020: Municipios / Alcaldías, población y superficie.

\begin{tabular}{|c|c|c|c|c|c|c|c|}
\hline \multirow[b]{3}{*}{$\begin{array}{c}\text { Zonas } \\
\text { metropolitanas }\end{array}$} & \multirow[b]{3}{*}{$\begin{array}{l}\text { Municiplos } \\
\text { / Alcaldias }\end{array}$} & \multicolumn{4}{|c|}{ Población } & \multirow{2}{*}{\multicolumn{2}{|c|}{ Superficie }} \\
\hline & & \multicolumn{2}{|c|}{2014} & \multicolumn{2}{|c|}{2020} & & \\
\hline & & Absoluta & $\begin{array}{c}\% \text { de la } \\
\text { Megalópolls }\end{array}$ & Absoluta & $\begin{array}{c}\% \text { de la } \\
\text { Megalópolis }\end{array}$ & $\mathrm{km}^{2}$ & $\begin{array}{c}\text { \% de la } \\
\text { Megalópolis }\end{array}$ \\
\hline \multicolumn{8}{|l|}{ Principales } \\
\hline Vale de México & 76 & $20,737,548$ & 45.6 & $21,668,606$ & 45.1 & 7,866 & 6.1 \\
\hline Puebla-Tlaxcala & 39 & $2,899,348$ & 6.4 & $3,155,186$ & 6.6 & 2,392 & 1.9 \\
\hline Toluca & 16 & $2,165,127$ & 4.8 & $2,391,681$ & 5.0 & 2,412 & 1.9 \\
\hline Quarétaro & 5 & $1,291,204$ & 28 & $1,485,822$ & 3.1 & 2,427 & 1.9 \\
\hline Cuernavaca & 8 & 971,685 & 21 & $1,041,766$ & 2.1 & 1,190 & 0.9 \\
\hline Sub-Total & 144 & $28,064,912$ & 61.7 & $29,743,061$ & 61.9 & 16.287 & 12.7 \\
\hline Otras ${ }^{1}$ & 50 & $2,654,959$ & 5.8 & $2,934,432$ & 6.1 & 5,340 & 4.1 \\
\hline $\begin{array}{l}\text { Resto de la } \\
\text { Megalópolis }\end{array}$ & 407 & $14,760,947$ & 32.5 & $15,391,688$ & 32.0 & 107,452 & 83.2 \\
\hline Total & 601 & $45,480,818$ & 100,0 & $48,069,181$ & 100.0 & 129,079 & 100,0 \\
\hline
\end{tabular}

\section{Notas:}

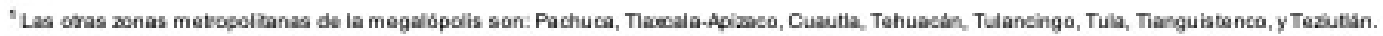

${ }^{2}$ E resto de la megabpolis comprende el sistama urbano-ural no integrado en zonas metropolitanas, de las entidades fuderatves de: Ciudad de Modico, Estado de Moboo, Gasajajato, Hidago, Morelos, Puebls, Queritaro y Tlaxcala.

Fuente: CONAPO-INEGI, 2018.

Cuadro $\mathrm{N}^{\circ} 2$.

Población ocupada en SIUCs en la Megalópolis, 2014-2018

\begin{tabular}{|c|c|c|c|c|}
\hline \multirow{3}{*}{$\begin{array}{c}\text { Zonas } \\
\text { metropolitanas }\end{array}$} & \multicolumn{4}{|c|}{ Población en SUIC } \\
\hline & \multirow[t]{2}{*}{2014} & \multirow[t]{2}{*}{2018} & \multicolumn{2}{|c|}{ Cambio } \\
\hline & & & Absoluto & $\%$ \\
\hline \multicolumn{5}{|l|}{ Principales } \\
\hline Valle de Mósico & 871,190 & 939,232 & 68,042 & 44.08 \\
\hline Puebla-Tlaxcala & 121,325 & 127,705 & 6,380 & 4.13 \\
\hline Querétaro & 108,036 & 120,025 & 11,989 & 7.77 \\
\hline Toluca & 84,641 & 90,684 & 6,043 & 3.92 \\
\hline Cuemavace & 36.638 & 36,663 & 25 & 0.02 \\
\hline Subtotal & $1,221,830$ & $1,314,309$ & 92,479 & 59.92 \\
\hline Otras" & 14.530 & 34,903 & 20.373 & 13.20 \\
\hline $\begin{array}{l}\text { Resto de la } \\
\text { Megalópolis }\end{array}$ & 300,989 & 342,482 & 41,494 & 26.88 \\
\hline Total & $1,537,349$ & $1,691,694$ & 154,346 & 100.0 \\
\hline \multicolumn{5}{|c|}{ 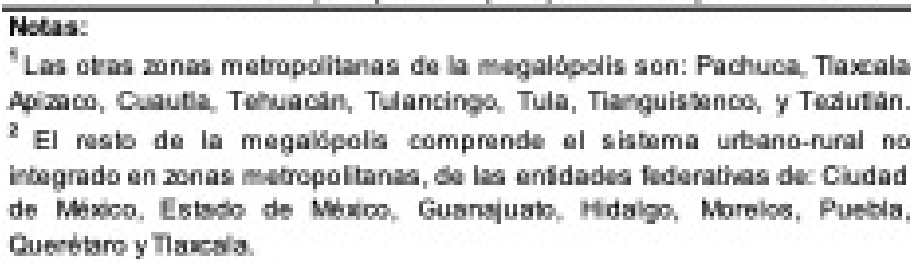 } \\
\hline
\end{tabular}

Fuente: Elaboración propia partir del DENUE 2014-2018. 
Cuadro $\mathrm{N}^{\circ} 3$.

Sectores, Grupos y Subsectores Intensivos en Uso de Conocimiento

\begin{tabular}{|c|c|c|}
\hline \multicolumn{2}{|c|}{ SIUC (Grupo) } & Industria da la madara \\
\hline \multirow{15}{*}{ 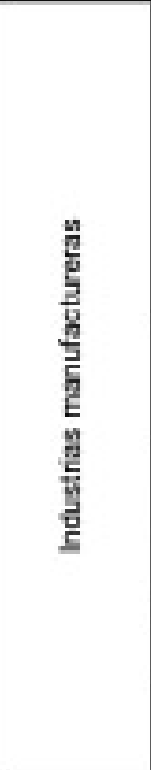 } & \multirow{7}{*}{$\begin{array}{l}\text { Industila quimice y } \\
\text { atras vincúadss }\end{array}$} & Industria de la madera. \\
\hline & & Industria del pepel. \\
\hline & & Impresión e industrias conexess. \\
\hline & & Felaricación de productos derivedos del petróleo y del carbón. \\
\hline & & industria quimica. \\
\hline & & industria dell pléstice y del hule. \\
\hline & & Fabricación de productos a base de minerales no metálicos. \\
\hline & \multirow{3}{*}{$\begin{array}{l}\text { Industria } \\
\text { metaimecánice }\end{array}$} & Industrias metallicas básicas. \\
\hline & & Fabricación de productos metálicos. \\
\hline & & Fabricación de maquinaria y equipo. \\
\hline & \multirow{2}{*}{$\begin{array}{l}\text { Industria electrónica y } \\
\text { aléctrica }\end{array}$} & $\begin{array}{l}\text { Fabricación de equipo de compulación, comunicación, medición y } \\
\text { de otros equigos, componentes y accesorios electrónicos. }\end{array}$ \\
\hline & & $\begin{array}{l}\text { Fabricación de accessarios, aparatos eléctricos y equipo de } \\
\text { generación de energia elóctrica. }\end{array}$ \\
\hline & $\begin{array}{c}\text { Automóniles, mótares } \\
y \text { autapavtes }\end{array}$ & Fabricación de equipo de transporte. \\
\hline & \multirow{2}{*}{$\begin{array}{l}\text { Resto de las } \\
\text { manufacturas }\end{array}$} & Fabricación de muebles, colchones y persianas. \\
\hline & & Otras industrias manufactureras. \\
\hline \multirow{3}{*}{\multicolumn{2}{|c|}{ Información en medios masivos }} & $\begin{array}{l}\text { Edición de periódicos, nevistas, llaros, software y otros materiales, y } \\
\text { edición de estas publicaciones integradas con la impresión. }\end{array}$ \\
\hline & & Industria filmica y del video, $e$ industria del sonida. \\
\hline & & Radio y televisión. \\
\hline \multirow{7}{*}{ 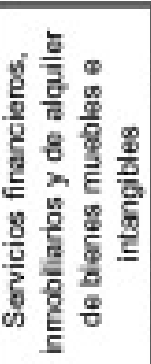 } & \multirow{4}{*}{$\begin{array}{c}\text { Serwicios financieros } y \\
\text { de seguros }\end{array}$} & Banca central. \\
\hline & & Institucianes de intermediación crediticla y financiera no bursatil. \\
\hline & & Actididades burgátiles, cambiarias y de imersión financiera. \\
\hline & & Companias de farzas, seguras y pensiones. \\
\hline & \multirow{3}{*}{$\begin{array}{l}\text { Senviclas inmobiNonios } \\
\text { y de aiquider de bienes } \\
\text { muebles e intangibies }\end{array}$} & Servicios inmobiliarios. \\
\hline & & Servicios de alquiler de bienes muebles. \\
\hline & & Sericios de alquiler de marcas registradas, patentes y franquicias. \\
\hline \multicolumn{3}{|r|}{ ios probesianales, ciertificas y técnicos } \\
\hline & & Comporatives \\
\hline
\end{tabular}

Fuente: Garrocho, 2013.

\section{Metodología}

Utilizamos el Análisis de Cambio y Participación Espacial (ACPE), porque permite examinar el desempeño económico de la Megalópolis, considerando su estructura espacial y su integración funcional a diversas escalas geográficas. En este marco, los microespacios de la Megalópolis operan como sistema espacio-sectorial y sus interrelaciones afectan la dinámica del empleo SIUCs. Este análisis es más realista que si se hiciera en un no-lugar abstracto: usualmente una hoja de cálculo vacía de contenido geográfico (Garrocho, 2013). 
De acuerdo al ACPE, las causas básicas del cambio del empleo SIUCs en los microespacios (municipios, alcaldías), son: $i$. Desempeño del mercado laboral de la región en la que se localizan los microespacios (mercados laborales dinámicos los impulsan, mercados lentos los frenan); ii. Especialización económica de los microespacios en sectores dinámicos o lentos en generación de empleos; y, iii. Ventajas competitivas de cada microespacio (Nazara \& Hewings, 2004). El estudio se hace a tres escalas: Megalopolitana, metropolitana y municipios/alcaldías (microespacial). Cada causa básica se ubica en espacio, sector, tiempo.

El ACPE surge como reacción a numerosas críticas al Cambio y Participación no-espacial (ACP) (desde Richardson, 1978; Loveridge \& Selting, 1998). Se destacaban limitaciones diversas, sobre todo, su carácter no-espacial: opera en ningún lugar. Con el ACPE la mayoría de las críticas han encontrado respuestas y soluciones, primordialmente la necesidad de incorporar al método la dimensión geográfica (Ramajo \& Márquez, 2008). Aportaciones notables utilizadas hoy día son: Nazara \& Hewings (2004) incluyen la estructura espacial de la zona de estudio; Le Gallo \& Kamarianakis (2011) consideran las interacciones intersectoriales; Ramajo \& Márquez (2008) desintegran el cambio económico de una región en tres componentes espaciales aditivos; Zaccomer \& Mason (2011), avanzan en resolver el problema de la estructura espacial.

Recientemente, el ACPE ha registrado avances adicionales y mostrado su utilidad para analizar la dinámica del empleo en Grecia (Psycharis et al., 2018), Europa (Kivi, 2019); Corea (Mo et al., 2020), México (Valdez, 2018; Rendón et al., 2019; Flores et al., 2018).

\section{Premisas Básicas del ACPE}

i. Todos los microespacios $j$ (v.g. municipios/alcaldías) son parte de una región referencial $k$ (v.g. la Megalópolis), pero también integran sistemas metropolitanos $m$.

ii. Los microespacios $j$ interactúan formando sistemas complejos que funcionan a diversas escalas espaciales. Consideramos tres escalas simultáneamente: la megalopolitana $k$, la metropolitana $m$ y la de los microespacios $j$;

iii. El cambio del empleo SIUCs se mide en términos de velocidad (tasa) y magnitud (empleos);

iv. Las interacciones de los microespacios $j$ varían en intensidad en función inversa a los costos de transporte. Es clave considerar la localización relativa de los microespacios $j$ y sus interrelaciones de cercanía/lejanía;

v. Las interacciones de los microespacios $j$ transmiten efectos económicos positivos/negativos (directos e indirectos) en los sistemas $k$ y $m$;

vi. Los cambios del empleo SIUCs en cada microespacio $j$ y en cada sector $i$, durante un cierto periodo t, se deben a tres causas distintas: Efecto Megalopolitano (desempeño del mercado laboral de k), Efecto de la Mezcla Sectorial (concentración laboral de $j$ en sectores dinámicos o lentos en generación de empleos) y Efecto de la Competitividad Local (ventajas/desventajas competitivas de $j$ ). Estos tres Efectos pueden tener comportamientos divergentes entre sí (v.g. ser positivos o negativos). Su sumatoria genera el Cambio Neto Total del empleo SIUCs en $j$. 
vii. El Efecto de la Competitividad Local resulta de la interacción de dos causas subsidiarias, que operan de manera diferenciada en el territorio: más intensamente en la escala metropolitana $m$ y con menor fuerza en la escala megalopolitana $k$. Estas causas son el Efecto Regional Neto Espacial (ERNE) y el Efecto Diferencial Espacial (EDE). El primero puede entenderse como el cambio del empleo $i$ en $j$ si la estructura sectorial de $j$ fuera igual a la de $m$ (y muy parecida a la de k). El Efecto Diferencial Espacial es un primer indicador de las ventajas/desventajas competitivas de $j$ respecto a $m$ y $k$;

viii.Los resultados del ACPE son valiosos como órdenes de magnitud de las causas del cambio del empleo SIUCs. Lo ideal es complementarlos con estudios cualitativos para develar "las causas de las causas". Realizar este tipo de estudios sobrepasa los alcances de este trabajo.

La formulación matemática del ACPE y la secuencia de los cálculos se presentan en la Figura $\mathrm{N}^{\circ} 2 . .^{9} \mathrm{El}$ ACPE se operó en la Estación de Inteligencia Territorial CHRISTALLER ${ }^{\circ}$ desarrollada en EI Colegio Mexiquense (Chávez \& Garrocho, 2018)..$^{10}$

Figura $\mathrm{N}^{\circ} 2$.

Proceso de cálculo del análisis Cambio y Participación Espacial y Tradicional

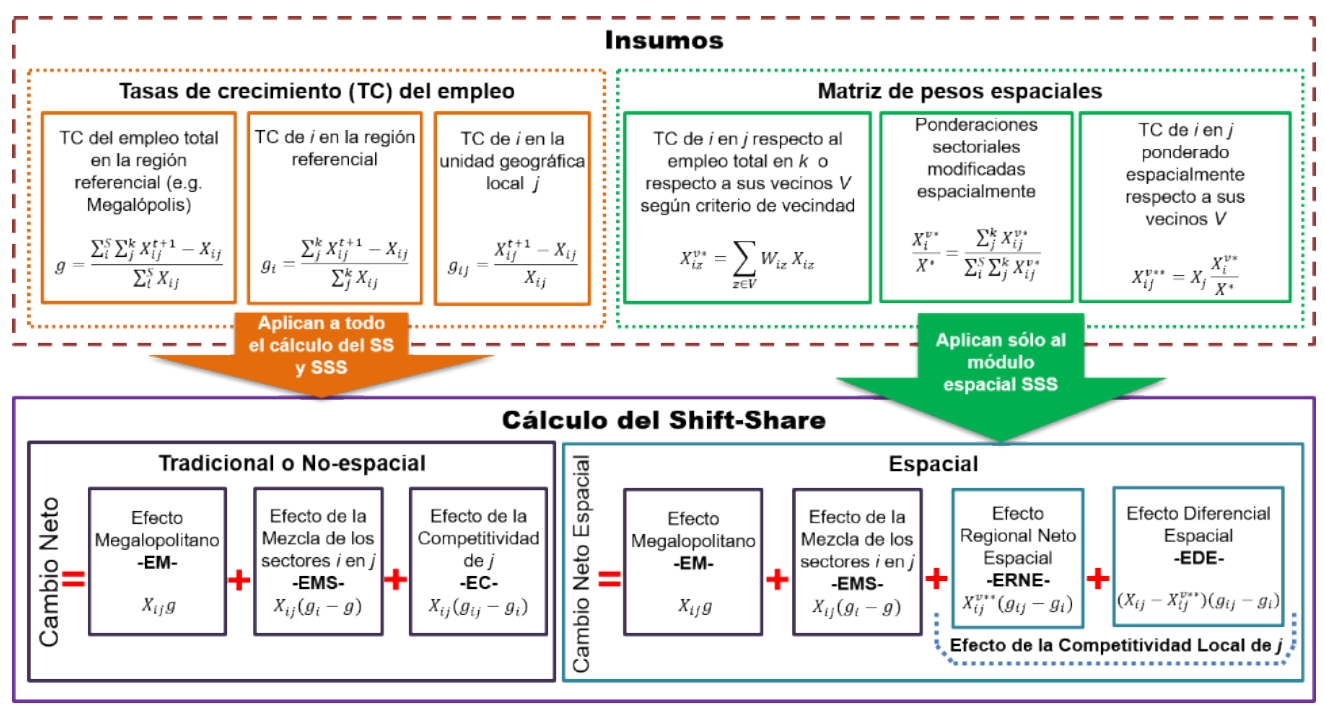

$\boldsymbol{X}_{i j}$ : Empleo en el $i$-ésimo sector, en la $j$-ésima unidad geográfica local en el periodo $t$. Es decir, el dato de empleo en un sector y en un municipio/alcaldia en el periodo inicial del análisis.

$X_{i j}^{t+1}$ : Empleo en el $i$-ésimo sector, en la $j$-ésima unidad geográfica local en el periodo $t+1$. Es decir, el dato de empleo en un sector y en un municipio/alcaldia en el periodo final del análisis.

$\boldsymbol{W}_{i j}$ : Matriz de pesos espaciales (e.g. matriz estandarizada por filas o distancia inversa), calculada para toda la región referencial (e.g. Megalópolis). S: Sectores Intensivos en Uso del Conocimiento (SIUC's). En la notación es el i-ésimo sector.

$\boldsymbol{k}$ : Región referencial (e.g. Megalópolis)

$z$. Vecinos de la unidad geográfica local $j$. El criterio de vecindad lo define el analista (e.g. matriz estandarizada por filas, distancia inversa u otro).

Notas:

SS = Cambio y Participación Tradicional o No-Espacial (ACP).

SSS = Cambio y Participación Espacial (ACPE).

Fuente: Elaboración propia.

\footnotetext{
Ver explicaciones matemáticas detalladas en Ramajo \& Márquez (2008); Valdez (2018); Rendón et al., (2019)

10 El sitio web de CHRISTALLER ${ }^{\circledR}$ es: http://www.christaller.org.mx/
} 


\section{Resultados ${ }^{11}$}

\section{La escala Metropolitana: Cambio Neto del empleo SIUCs}

La ZMVM era el nodo SIUCs dominante del sistema Megalopolitano en 2018: concentraba más de la mitad (55.5\%) del empleo SIUCs, y 77.7 por ciento si sólo consideramos nuestro universo de estudio (Cuadro N4). Entre 2014-2018, la Megalópolis registró un Cambio Neto positivo de empleo SIUCs en cuatro ZM, equivalente a 92,479 empleos (7.6\%) (Cuadro No4).

Resaltan varios puntos. Uno, la ZMVM no es la más dinámica en crecimiento de empleo SIUCs. Esto es normal, dadas sus dimensiones: a mayor tamaño la tendencia es a crecer más lento, pero en magnitudes mayores. Lo interesante es que a pesar de su tamaño, la ZMVM ocupa el segundo lugar en velocidad de Cambio Neto (7.8\%): generó poco más de 68 mil empleos. Cerrando cifras: tres de cada cuatro nuevos empleos SIUCs de la Megalópolis (73.6\%) se localizaron en la ZMVM (Cuadro No 4). Como indica la teoría: las concentraciones de empleos SIUCs son magnetos de personas calificadas.

El segundo punto es el desempeño de la ZMQ. No sólo registra el Cambio Neto más rápido de la Megalópolis (11.1\%), sino que en términos absolutos superó claramente a dos ZM con mucha mayor población: la ZMPT y la ZMT (Cuadro N 1). La población total de la ZMQ en 2014 equivalía a 45 por ciento de la ZMPT y 60 por ciento de la ZMT. Con todo, la brecha de empleos SIUCs entre las ZMQ y ZMPT se reduce rápidamente: de alrededor de 13 mil empleos en 2014 a favor de la ZMPT a 7 mil en 2018 (Cuadro No 4). Por otro lado, es contundente la superioridad de la ZMQ sobre la ZMT en empleo SIUCs, tanto en velocidad como en magnitud: si en 2014 la ZMQ tenía 24 mil empleos más que la ZMT, en 2018 amplió su ventaja a 30 mil. Esto confirma la propuesta teórica de que el tamaño de la población no siempre es un buen predictor de la generación de empleo SIUCs. Adicionalmente, la teoría propone que el empleo SIUCs impacta la productividad. Así ocurre, la ZMQ supera a las demás ZM en su PIB per cápita: a la ZMVM (11.2\%), ZMC (47.2\%), ZMPT (51.7\%) y ZMT (54.9\%). También las supera en porcentaje de viviendas con automóvil, computadora e internet (CITIBANAMEX, 2017).

A partir de esta sección nos referiremos a las zonas metropolitanas por sus acrónimos: Valle de México (ZMVM), Puebla-Tlaxcala (ZMPT), Querétaro (ZMQ), Toluca (ZMT), Cuernavaca (ZMC). 
Cuadro $\mathrm{N}^{\circ} 4$.

Población ocupada en SIUCs en la zona de estudio: Cambio Neto por Zona Metropolitana y en la Megalópolis, 2014-2018

\begin{tabular}{|c|c|c|c|c|c|c|c|c|}
\hline \multirow{3}{*}{$\begin{array}{c}\text { Zonas } \\
\text { Metropolitanas }\end{array}$} & \multicolumn{8}{|c|}{ Población Ocupada en SIUC } \\
\hline & \multirow{2}{*}{2014} & \multirow{2}{*}{2018} & \multicolumn{2}{|c|}{$\begin{array}{l}\text { Participación } \\
\text { respecto a (\%): }\end{array}$} & \multicolumn{2}{|c|}{ Cambio Neto } & \multicolumn{2}{|c|}{$\begin{array}{l}\text { Participación del Cambio } \\
\text { Neto respecto a }(\mathrm{Y} / \mathrm{s}\end{array}$} \\
\hline & & & $\begin{array}{c}\text { Principales } \\
\text { ZM } \\
\end{array}$ & Megalopolis & Absolute & $\%$ & $\begin{array}{c}\text { Principales } \\
\text { ZM } \\
\end{array}$ & Megalópolis \\
\hline \multicolumn{9}{|l|}{ Principales } \\
\hline Vale de Midice & 871,190 & 939.232 & 71.5 & 55.5 & 68,042 & 7.8 & 73.6 & 44.1 \\
\hline Puebla-Tlancala & 121,325 & 127,705 & 9.7 & 7.5 & 6,380 & 5.3 & 6.9 & 4.1 \\
\hline Querétaro & 108,006 & 120,025 & 9.1 & 7.1 & 11,989 & 11.1 & 13.0 & 7.8 \\
\hline Toluca & 84,641 & 90,684 & 6.9 & 5.4 & 6,043 & 7.1 & 6.5 & 3.9 \\
\hline Cuernavaca & 36,638 & 36,663 & 2.8 & 22 & 25 & 0.1 & 0.0 & 0.0 \\
\hline Subtotal & $1,221,890$ & $1,314,309$ & 100.0 & 77.7 & 92,479 & 7.6 & 100.0 & 59.9 \\
\hline Otras ${ }^{1}$ & 14,530 & 34,903 & NA & 21 & 20,373 & 140.2 & NA & 13.2 \\
\hline $\begin{array}{l}\text { Resto de la } \\
\text { Megalópolis }\end{array}$ & 300,969 & 342,482 & N.A & 20.2 & 41,494 & 13.8 & NA & 26.9 \\
\hline Total & $1,537,349$ & $1,691,694$ & N.A & 100.0 & $154,345.5$ & 10.0 & NA & 100.0 \\
\hline
\end{tabular}

Fuente: Elaboración propia a partir de DENUE 2014-2018.

El tercer punto, es el declive de la ZMPT. A pesar de (o quizá por) tener una población superior a los tres millones de habitantes, la ZMPT, siempre fuerte competidora, no genera ventajas competitivas importantes para el empleo SIUCs. No sólo la superó la ZMQ, sino que en el periodo también fue rebasada en velocidad del Cambio Neto por la ZMT, que casi la igualó en magnitud de crecimiento. En consecuencia: el PIB per cápita de la ZMPT es menos de la mitad que el de la ZMQ (CITIBANAMEX, 2017). Recordar ejemplos de ciudades en situación de desastre, que parecían demasiado poderosas para caer (e.g. Detroit: ver revisión teórica).

De la ZMC no vale la pena hablar. A pesar de contar con una población total de alrededor de un millón de habitantes, apenas generó 25 empleos SIUCs, que para efectos prácticos es cero. Su futuro está en sectores de consumo local y en algunos de consumo para población externa (e.g. servicios turísticos, casas de retiro).

El Cambio Neto del Empleo tiene varias causas que operan a escalas espaciales distintas. Se examinan a continuación.

\section{Las escalas Megalopolitana y Metropolitana}

Efecto Megalopolitano. Este Efecto es positivo para todas las ZM. Es decir, todas fueron impulsadas por el desempeño agregado de la Megalópolis para generar empleos, pero en magnitudes contrastantes (Cuadro N05). La más beneficiada fue la ZMVM, que tiene una importancia eclipsante en la región (y en el país) y un desempeño autocorrelacionado: en la Megalópolis el Efecto Megalopolitano es, en mucho, el efecto de la ZMVM, aunque no se puede desdeñar la influencia de los otros núcleos de la región. En la ZMVM siete de cada diez empleos SIUCs se debieron al 
Efecto Megalopolitano, mientras que en las demás ZM la influencia fue menor: varió de $6.9 \%$ en la ZMT a 9.9\% en la ZMQ. (Cuadro No5).

Cuadro No 5.

Cambio del empleo SIUCs por efectos de alcance megalopolitano

\begin{tabular}{|c|c|c|c|c|c|}
\hline $\begin{array}{c}\text { Zona } \\
\text { Metropolitana }\end{array}$ & $\begin{array}{c}\text { Cambio } \\
\text { Neto }\end{array}$ & $\%$ & $\begin{array}{c}\text { Efecto } \\
\text { Megalopolitano }\end{array}$ & $\%$ & $\begin{array}{l}\text { Efecto de } \\
\text { la Mezcla } \\
\text { Sectorial }\end{array}$ \\
\hline Valle de México & 68,042 & 73.6 & 65,939 & 71.3 & 2,103 \\
\hline Puebla-Tlaxcala & 6,380 & 6.9 & 9,183 & 9.9 & $-2,803$ \\
\hline Querétaro & 11,989 & 13.0 & 8,177 & 8.8 & 3,812 \\
\hline Toluca & 6,043 & 6.5 & 6,406 & 6.9 & -363 \\
\hline Cuemanaca & 25 & 0.0 & 2,773 & 3.0 & $-2,748$ \\
\hline Total general & 92,479 & 100.0 & 92,479 & 100.0 & 0.0 \\
\hline
\end{tabular}

Fuente: Elaboración propia

Efecto de la Mezcla Sectorial. Este efecto es muy interesante porque registra valores negativos y positivos. ${ }^{12}$ Dado el Cambio Neto de empleo SIUCs en la ZMVM y en la ZMQ, era de esperarse que también registraran buen desempeño en la generación de empleo SIUCs por Efecto de su Mezcla Sectorial (Cuadro No 5). Así fue, estas dos ZM son las únicas de la Megalópolis que registran efectos positivos: se especializan en SIUCs dinámicos.

La ZMQ se beneficia del Efecto de la Mezcla Sectorial en mayor medida que la ZMVM, lo que significa que cuenta con una cartera de SIUCs más dinámicos que el nodo clave de la Megalópolis (aunque en magnitud, los de la ZMQ produzcan un cambio menor del empleo). Entre otros SIUCs dinámicos de la ZMQ, destacan la Fabricación de equipo de transporte (726 empleos, muchos en la industria aeroespacial), Fabricación de productos metálicos (501 empleos), Servicios profesionales, científicos y técnicos (430 empleos), Industria del plástico y del hule (379 empleos), e Instituciones bancarias (240 empleos). Todos estos SIUCs tienen fuertes efectos multiplicadores en el resto del empleo o son fundamentales para apoyar la actividad económica.

La ZMVM registró un potente Efecto de su Mezcla Sectorial en varios SIUCs, pero destacamos los dos más dinámicos: Servicios profesionales, científicos y técnicos (3,788 empleos) y Corporativos (561 empleos). El efecto multiplicador de estos dos SIUCs es muy elevado y refleja ventajas locacionales, económicas y políticas de la CDMX, por ser la capital del país.

Otra clave del análisis del Efecto de la Mezcla Sectorial, es que produce valores negativos en las ZMPT, ZMT y ZMC. Por tanto, estas ciudades han concentrado su empleo en SIUCs poco dinámicos en el contexto Megalopolitano y tienen débiles vínculos sectoriales con la ZMVM. La ZMT registra un saldo negativo por Efecto de su Mezcla Sectorial (-363 empleos). Lo preocupante es que se concentra en Fabricación de equipo de transporte ( -275 empleos), que era uno de los SIUCs propulsores de la ciudad. Esto parece poco si se compara con la catástrofe de la ZMPT y la

Por extensión del texto nos concentramos en los microespacios más relevantes. Se puede acceder a todos los mapas, datos y resultados en: http://christaller.org/index.php/proyectos-de-investigacion/datos-en-extenso/shift-share-spatial (fecha consulta: 7 de diciembre de 2020). 
ZMC. La primera perdió -2,803 empleos por Efecto de su Mezcla Sectorial y, lo peor: $30.1 \%$ de la pérdida se registró en Servicios profesionales, científicos y técnicos, fundamentales en la economía del conocimiento (como indica la teoría). En el caso de la ZMC, el escenario de desastre por Efecto de su Mezcla Sectorial es generalizado. Las ZMPT, ZMT y la ZMC están en declive.

\section{La escala intrametropolitana}

Efecto de la Competitividad Local. Este Efecto toma en cuenta, simultáneamente, las estructuras espaciales de la Megalópolis y las de cada ZM. Por la cercanía, es más intenso en la escala intrametropolitana. Priorizamos los microespacios más competitivos, así como los sectores más y menos beneficiados de las condiciones de competitividad de cada uno.

Los microespacios Top-5 en Competitividad de la ZMVM, en orden descendente, son alcaldías de la CDMX: Cuauhtémoc, Álvaro Obregón, Miguel Hidalgo, Cuajimalpa y Benito Juárez. Son vecinas y conforman una amplia zona en el centro-oeste de la ciudad, con una superficie de 271 kilómetros cuadrados. Todos sus ERNE y EDE son positivos: estos microespacios $j$ están creciendo en empleo SIUCs por encima de la escala Metropolitana $m$ y Megalopolitana $k$. También significa que este crecimiento se debe a ventajas competitivas que ofrece cada $j$ a los SIUCs $i$. Estas ventajas incluyen las interacciones de $j$, principalmente con $m$, pero también con $k$. Es decir, para estos microespacios $j$ de la ZMVM la estructura espacial intrametropolitana es clave y la están aprovechando para impulsar su empleo SIUCs. Esto confirma que los microespacios $j$ operan como sistema, no como islas: la localización y las interacciones importan (ver metodología).

La alcaldía Cuauhtémoc registró un impulso de 11,203 empleos en tres SIUCs relacionados con finanzas: Instituciones bancarias; Compañías de fianzas, seguros y pensiones; Actividades bursátiles, cambiarias y de inversión financiera. En este microespacio se localiza el Banco de México (el banco central) y la Bolsa Mexicana de Valores, lo que genera un ecosistema financiero (ver revisión teórica). También Cuajimalpa (localización de la parte más corporativa de Santa Fe, sede de múltiples agencias de capital: Serfimex, Exitus) ofrece notables ventajas competitivas a actividades financieras de alcance nacional (2,645 empleos por Efecto de su Competitividad Local). Otros microespacios que también generan ventajas competitivas a los sectores de finanzas son Miguel Hidalgo (9,494 empleos; Management Asset, Contigo), Benito Juárez (5,689; Aktiva, Emprendedores) y Álvaro Obregón (5,991; Itaca, Multiactiva). Miguel Hidalgo también es competitiva para la Industria química (1,008 empleos; Corporación Mexicana de Polímeros), y Benito Juárez atrae servicios inmobiliarios (ahí se localiza el World Trade Center y zonas residenciales importantes: las colonias Del Valle, Nápoles, San José Insurgentes; 465 empleos). Álvaro Obregón también ofrece ventajas competitivas a actividades de Radio y Televisión (Televisa San Ángel; 1,581 empleos) ${ }^{13}$. La teoría explica esta concentración por la reducción de los costos de transmisión de información no-codificada ("contactos cara a cara").

No todo son cambios positivos. Los microespacios Miguel Hidalgo, Cuauhtémoc, Benito Juárez y Álvaro Obregón han registrado desventajas competitivas para Servicios profesionales, científicos y técnicos (en conjunto registran -26,095 empleos por Efecto de la Competitividad Lo-

Esta empresa enfrenta problemas financieros desde la llegada de plataformas como Netflix (https://expansion.mx/tecnologia/2021/04/15/ para-competir-con-netflix-televisa-debe-crear-un-nuevo-house-of-cards fecha de consulta: 20 de octubre de 2020). 
cal). Además, sus pérdidas por Competitividad se registran en SIUCs en los que eran dominantes: Álvaro Obregón en Corporativos y, junto con Miguel Hidalgo, en la Industria fílmica, del video y la industria del sonido. La entrada de nuevas plataformas tecnológicas incrementó la competencia, diversificó los sitios de producción a escala global, innovó el modelo de negocio (la teoría habla de globalización y cambios tecnológicos disruptivos). Cuauhtémoc se contrae en Impresión e industrias conexas (cuando ha sido localización de editoriales y periódicos importantes, como Grijalbo, Porrúa, Revista Nexos, La Jornada, lo que refleja la importancia de Internet y las redes sociales: otro cambio tecnológico disruptivo). Benito Juárez pierde ventajas en Radio y Televisión (e.g. Radio Educación, Radio UNAM, Radio Centro: víctimas de las Tecnologías de la Información y la Comunicación). En estos sectores los microespacios mencionados registran ERNE y EDE negativos, lo que significa desaceleración de empleos respecto a las escalas Metropolitana y Megalopolitana, por pérdida de Competitividad Local.

En la ZMQ, el microespacio más competitivo es Querétaro (la capital del estado), que ha difundido el crecimiento del empleo SIUCs a sus microespacios vecinos: El Marqués (que cuenta con gran parte del aeropuerto internacional y varios parques industriales: Bernardo Quintana) y Corregidora (con su Parque Industrial Balvanera, donde se localizan industrias importantes: Siemens, TetraPak, Sika). Estos dos microespacios muestran valores EDE positivos y elevados: están aprovechando su interacción con Querétaro.

Querétaro ofrece condiciones muy competitivas para los SIUCs más dinámicos de su ZM: Fabricación de aparatos eléctricos (Samsung; 1,122 empleos); Servicios profesionales, científicos y técnicos (859 empleos): en este microespacio se localizan diversos centros de investigación de las instituciones más prestigiadas del país (CINVESTAV, UNAM), varios parques industriales y tecnológicos como "El Marqués", y la poderosa Industria del papel (Packaging Logistics; 697 empleos) ${ }^{14}$.

Existen actividades de alto contenido tecnológico que no encuentran ventajas en la ZMQ, como la Fabricación de equipo de computación y componentes electrónicos. Particularmente en Querétaro (-1,474 empleos), pero también en Corregidora (-389) y El Marqués (-191). En este SIUC los tres microespacios forman un territorio perdedor, con grandes desventajas competitivas respecto a la Megalópolis. El Marqués también debe atender la pérdida de competitividad en Servicios profesionales, científicos y técnicos (-848), fundamentales para la productividad. Tanto su ERNE como su EDE son negativos (éste tiene un valor muy importante para la escala laboral del microespacio -847): El Marqués no les ofrece ventajas competitivas a estos SIUCs, que sí les ofrecen Querétaro y la Megalópolis.

Veamos qué ocurrió en la ZMPT con su Efecto de la Competitividad Local. Sus bajos valores de ERNE implican desaceleración de SIUCs en microespacios, respecto a la escala Metropolitana $m$ y Megalopolitana $k$. Como registra valores positivos (pero bajos) de EDE en sus principales microespacios y SIUCs, se deduce que están en un proceso de pérdida de ventajas competitivas, incluyendo debilitamiento de interacciones espaciales, sobre todo con la ZMVM (a pesar de que la ZMPT se conecta con la ZMVM mediante 135 kilómetros de autopista de altas especificaciones).

14 CINVESTAV: Centro de Investigación y de Estudios Avanzados; UNAM: Universidad Nacional Autónoma de México. 
Se salva el microespacio Cuautlancingo, tuvo un Cambio Neto del empleo notable: 3,173 empleos SIUCs. Esto equivale a poco más de once veces el Cambio Neto Total de Puebla (282 nuevos empleos). Cuautlancingo ofrece grandes ventajas en Fabricación de Equipo de Transporte (ahí se ubica la planta Volkswagen): 1,451 nuevos empleos por Competitividad Local y a Instituciones bancarias (366 empleos), lo que se vincula con el auge de empresas localizadas en parques y corredores industriales del microespacio. Sin embargo, Cuautlancingo registra desventajas competitivas para la Industria del plástico y del hule (-1,567 empleos, con ERNE y EDE negativos). Explicar esto requiere investigación cualitativa: este SIUCs se vincula con el automotriz. Por su parte, Puebla tuvo un mal desempeño como generador de empleo SIUCs, excepto en Instituciones bancarias (843 empleos por Competitividad Local), ligado a la actividad económica de la ZMPT, pero también al gran tamaño de su población. Resulta dramática la enorme pérdida de competitividad de Puebla en Servicios inmobiliarios (-1,073 empleos: ERNE y EDE negativos que implican que Puebla ofrece desventajas competitivas a este sector). Es raro, la ZMPT es la cuarta ciudad más poblada de México y no se ve afectada por problemas graves de inseguridad.

Al interior de la ZMT, Toluca (la capital del estado) sigue siendo el microespacio que ofrece las mayores ventajas a la localización de empleo SIUCs. No obstante, el desempeño de la ZMT fue muy inferior al de la ZMVM y la ZMQ. La ZMT registró un Cambio Neto de apenas 1,360 nuevos empleos SIUCs (80\% menos que la ZMQ) y su desempeño por Efecto de la Competitividad Local fue muy pobre, comparado con microespacios como Querétaro o Cuautlancingo. Es intrigante: la ZMT se localiza a cuarenta minutos de la ZMVM (un mercado de 22 millones de habitantes y el principal centro de empleo SIUCs del país) conectada a la ZMVT por una autopista excelente. En Toluca destacan dos SIUCs: Industria Química (e.g. especialmente farmacéutica: Pfizer, Signa-Apotex; 863 empleos por Efecto de la Competitividad Local) y Fabricación de aparatos eléctri$\cos$ (Bosch, Alstom Grid; 524 empleos). Ambos sectores han encontrado ventajas competitivas en Toluca desde hace décadas.

Un problema para la ZMT es que no aparece Fabricación de equipo de transporte (que sí registra la ZMPT) como beneficiario de la competitividad de microespacios como Toluca o Lerma. Incluso fue el sector que más empleo perdió por falta de competitividad de estos microespacios: $-1,290$ empleos. En Toluca se localizan armadoras de automóviles (Fiat-Chrysler) y motores (General Motors). Sin embrago, los modelos que armó Fiat-Chrysler en Toluca en el periodo de estudio no fueron exitosos: Jeep Compass tuvo que modificar su estrategia de competencia. ${ }^{15}$ Por su parte el Fiat 500 se dejó de producir en Toluca en 2019'16; y, la Dodge Journey fue calificada como "un dinosaurio que se resiste al meteorito"17.

Los ERNE y EDE de Toluca y Lerma son negativos en Fabricación de equipo de transporte, en los que históricamente registraban ventajas competitivas. Las ventajas se han convertido en desventajas. Toluca-Lerma son zona de desastre laboral en este SIUCs que impacta numerosos empleos directos e indirectos. Quizá el sector automotriz encuentra más ventajas competitivas en El Bajío y en la frontera con Estados Unidos, pero el contrargumento es que la ZMPT sigue siendo

\footnotetext{
https://www.autologia.com.mx/2019/11/05/jeep-compass-2020-analisis-de-gama-precios-versiones-y-equipamiento-en-mexico/ (fecha de consulta: 15 de enero de 2020).

16 https://noticias.autocosmos.com.mx/2019/11/25/fiat-500-abarth-se-despide-de-la-produccion-en-mexico-con-una-edicion-muy-especial (fecha de consulta: 10 de enero de 2020).

17 https://www.motorpasion.com.mx/industria/dodge-journey-opiniones-analisis-mexico (fecha de consulta: 20 de enero de 2020)
} 
competitiva en este SIUCs ${ }^{18}$. Toluca también perdió competitividad en Servicios profesionales, científicos y técnicos (-1,140 empleos, con ERNE y EDE negativos, el segundo es masivo). Esto tiene dos explicaciones, al menos. Una, que numerosa población capacitada vive en Metepec (uno de los microespacios con más alto nivel de vida de México, localizado en el acceso a la autopista que va a la CDMX), pero trabaja en los importantes corporativos de Santa Fe (Cuajimalpa: en la ZMVM) (Garrocho, 2011). Dos, la reducción de contrataciones en la Universidad Autónoma del Estado de México (una de las de mayor matrícula del país), debido a su delicada situación financiera.

Los demás microespacios de la ZMT registraron un desempeño muy pobre en generación de empleo SIUCs. San Mateo Atenco (el segundo microespacio de la ZMT en empleo SIUCs) registró un Cambio Neto de apenas 707 empleos: la quinta parte que El Marqués (ZMQ) o Cuautlancingo (ZMPT). La involución del empleo SIUCs de los dos microespacios con "mejores" registros de la ZMT (Toluca y San Mateo) se debe a un declive metropolitano en estas actividades (sus valores de ERNE y EDE son muy bajos), a pesar (o quizá por razón) de su cercanía a la ZMVM. En ocasiones la cercanía eclipsa: la ZMT podría ser parte funcional de la ZMVM (zona dormitorio de empleos SIUCs: especialmente Metepec). Como indica la teoría: el costo de interactuar se reduce con la proximidad.

La ZMC tuvo un desempeño insignificante como generadora de empleo SIUCs. Incluso concentró sus pérdidas en un sector clave: Servicios profesionales, científicos y técnicos. El estado de Morelos (Cuernavaca es su capital) ha sido de los más peligrosos del país en secuestro. Esto puede estar inhibiendo su atracción de talento, a pesar de las importantes amenidades de la ciudad (ver revisión teórica).

\section{Aportaciones, discusión y conclusiones}

Este texto ofrece diversas aportaciones. En términos empíricos, muestra que la ZMPT y la ZMT están en proceso de decadencia en empleo SIUCs. Esto es grave: son la cuarta y quinta ciudades más pobladas del país y deben ser motores de crecimiento regional/nacional en la economía del conocimiento. Sin embargo, registran serios problemas de integración a la Megalópolis. La buena noticia es que la ZMVM y la ZMQ son ciudades vibrantes en empleo SIUCs, intensamente integradas entre sí. En estas ciudades se detectaron microespacios y SIUCs dinámicos y otros que deben reforzarse. Por su parte, el destino reconocido de la ZMC es fortalecerse lejos de los SIUCs: en sectores de servicios de exportación regional, como el turismo o servicios de retiro (GMC, 2016).

En términos de políticas público-privadas de integración, la prioridad no es ampliar la infraestructura carretera o el transporte para impulsar la interacción entre ciudades. Salvo el internet (banda 5G), el tema está bajo control. Del ACPE derivamos dos prioridades: $i$. Fortalecer las interacciones funcionales de los microespacios metropolitanos (especialmente en la ZMVM, mediante, por ejemplo: articulación de cadenas de valor, incentivos para la relocalización de actividades); y ii. Impulsar en la escala megalopolitana las interacciones institucionales (e.g. coordinación entre gobiernos) y culturales (e.g. coordinación entre empresas para alinear valores, actitudes, prácti-

El Bajío es una potente región productiva situada en el centro-oeste de México. La Frontera Norte es clave para el país, porque lo conecta con los Estados Unidos. 
cas) (ver: Meijers et al., 2018). El objetivo es que la Megalópolis opere como un ecosistema de competencia colaborativa que produzca sinergias e innovación (Brown et al., 2019; Garrocho, 2013).

En términos de generación de conocimiento, el empleo SIUCs no debe pensarse como sistema multisectorial, sino como sistema espacio-sectorial multiescalar. La escala geográfica deconstruye circunstancias y entornos, estructura información desde ángulos alternativos, genera hallazgos, facilita diseñar acciones de política espacio-sectorial. Dos ejemplos. Al pensar los SIUCs de manera multiescalar, emergió el sorprendente desempeño de la ZMQ y del microespacio Querétaro: ¿Acaso será la ciudad bisagra que articula El Bajío, la Frontera Norte con USA y la Megalópolis? ¿Está aprovechando economías de integración derivadas de otros sistemas de ciudades? Este tema ya lo estamos explorando. Segundo ejemplo. El ACPE permitió traducir argumentos conceptuales genéricos en Efectos concretos en el empleo, transformarlos en datos, llevarlos a la escala microespacial y luego a la de empresas y productos específicos. Este enfoque deductivo permitió encontrar algunas causas últimas del cambio del empleo SIUCs ("las causas de las causas"). La muestra más clara es la pérdida de Competitividad de la ZMT en Fabricación de equipo de transporte. La razón radica, en gran parte, en que una empresa global, Fiat-Chrysler, armó modelos poco exitosos. Las causas últimas del cambio del empleo SIUCs en una gran ciudad como la ZMT, pueden localizarse en fallas de diseño que ocurren a miles de kilómetros de distancia (e.g. Milán o Michigan): ejemplo del "Efecto Mariposa" en la economía megalopolitana.

Se contestaron las preguntas cuánto, dónde, en qué sectores, cuándo y por qué cambió el empleo SIUCs en la Megalópolis, sus principales ciudades y en sus microespacios intrametropolitanos, entre 2014-2018. Se encontró que el tamaño de la población no siempre es un buen predictor de la generación de empleo SIUCs, como lo muestra la ZMQ, que resultó una ciudad notablemente competitiva. Querétaro también demuestra que la integración a la Megalópolis puede superar a la proximidad a grandes ciudades, como la ZMPT y la ZMT. Se confirma la preponderancia de la ZMVM como magneto auto-reforzante de empleo SIUCs.

Es cierto que no hay teoría que explique integralmente el desarrollo diferenciado de las ciudades, pero tenemos factores claves que parecen favorecer las concentraciones de SIUCs. Algunos, como las estructuras económica y espacial, y la integración funcional se exploraron en este trabajo. Para avanzar la teoría sobre economías de integración en ciudades mexicanas, la agenda de investigación debe orientarse a descifrar el papel de la ZMQ como ciudad bisagra entre El Bajío, la Frontera Norte y la Megalópolis.

\section{Referencias}

ALMEJO, R., \& CAMPOS, M. Especialización y desempeño en sectores de uso intensivo del conocimiento de las ciudades mexicanas, 2000-2010. Consejo Nacional de Población, Ciudad de México, 2013.

ARRIBAS-BEL, D., \& SANZ-GRACIA, F. The validity of the monocentric city model in a polycentric age: US metropolitan areas in 1990, 2000 and 2010. Urban Geography, 2014, Vol. 35, No 7, p. $980-$ 997. https://doi.org/10.1080/02723638.2014.940693 
BAILY, M. N., \& MONTALBANO, N. Clusters and innovation districts: Lessons from the United States experience. Economic Studies at Brookings Institutions, 2018.

BROWN, P., BOCKEN, N., BALKENENDE, R. Why do companies pursue collaborative circular oriented innovation? Sustainability, 2019, Vol. 11, № 3, p. 635. https://doi.org/10.3390/su11030635

BURGER, M. J., \& MEIJERS, E. J. Agglomerations and the rise of urban network externalities. Papers in Regional Science, 2016, Vol. 95, No 1, p. 5-15. https://doi.org/10.1111/pirs.12223

CAMAGNI, R., CAPELLO, R., \& CARAGLIU, A. Static vs. dynamic agglomeration economies: Spatial context and structural evolution behind urban growth. In Capello R. (eds) Seminal studies in regional and urban economics. Springer, Cham, 2017. p. 227-259. https://doi.org/10.1007/978-3319-57807-1_12

CHÁVEZ, T., \& GARROCHO, C. Christaller: Estación de Inteligencia Territorial. Geografía y Sistemas de Información Geográfica, 2018, Vol. 10, p. 29-50.

CITIBANAMEX. Indicadores Regionales de Actividad Económica (IRAE). Citibanamex, CDMX, 2017.

COMBES, Pierre-Philippe; GOBILLON, Laurent. The empirics of agglomeration economies. In Handbook of regional and urban economics. Elsevier, 2015. p. 247-348. https://doi.org/10.1016/ B978-0-444-59517-1.00005-2

CONAPO-INEGI. Proyecciones de la población de México. Consejo Nacional de Población e Instituto Nacional de Estadística, Geografía e Informática, México, 2018.

DADASHPOOR, H., \& MALEKZADEH, N. Driving factors of formation, development, and change of spatial structure in metropolitan areas: A systematic review. Journal of Urban Management, 2020, Vol. 9, No 3, p. 286-297. https://doi.org/10.1016/j.jum.2020.06.005

DAVIS, D., \& DINGEL, J. The comparative advantage of cities. Journal of International Economics, 2020, Vol. 123, p. 103291. https://doi.org/10.1016/j.jinteco.2020.103291

DIAMOND, J. Colapso: por qué unas sociedades perduran y otras desaparecen. Debate, 2018.

DURANTON, G., \& PUGA, D. Micro-foundations of urban agglomeration economies. In Handbook of regional and urban economics. Elsevier, 2004. p. 2063-2117. https://doi.org/10.1016/S15740080(04)80005-1

FLORES, M., MEDELLÍN, S., \& VILLARREAL, A. Global Markets and the Role of Geographical Proximity in Mexico's Employment Growth. Growth and Change, 2018, Vol. 49, № 3, p. 548-568. https:// doi.org/10.1111/grow.12248

FRITSCH, M., \& WYRWICH, M. Is innovation (increasingly) concentrated in large cities? An international comparison. Research Policy, 2021, Vol. 50, No 6, p. 104237. https://doi.org/10.1016/j.respol.2021.104237. 
GARROCHO, C. Dinámica de las ciudades de México en el siglo XXI: cinco vectores clave para el desarrollo sostenible. El Colegio Mexiquense, 2013.

GARROCHO, C. Población flotante, población en movimiento. Consejo Nacional de Población, México, 2011.

GARROCHO, C., \& SOBRINO, L. J. Ciudades sostenibles en México: ¿qué hacer? En: Cambio climático, ciudad y gestión ambiental. El Colegio de México, México, 2018.

GLAESER, E. L. El triunfo de las ciudades. Penguin Random House, 2011.

GLAESER, E. L., PONZETTO, G. A., \& ZOU, Y. Urban networks: Connecting markets, people, and ideas. Papers in Regional Science, 2016, Vol. 95, No 1, p. 17-59. https://doi.org/10.1111/pirs.12216

GMC. Plan de Desarrollo Municipal, 2016-2018. Gobierno Municipal de Cuernavaca, México. 2016.

GONTERO, S., \& ALBORNOZ, S. La identificación y anticipación de brechas de habilidades laborales en América Latina. Experiencias y lecciones, serie Macroeconomía del Desarrollo, 2019, № 199. Naciones Unidas Comisión Económica para América Latina y el Caribe (CEPAL), 2019.

HASSINK, R., \& GONG, H. New economic geography. The Wiley Blackwell Encyclopedia of Urban and Regional Studies, 2019, p. 1-6. https://doi.org/10.1002/9781118568446.eurs0222

JOHANSSON, B., \& QUIGLEY, J. M. Agglomeration and networks in spatial economies. In In: Florax R.J.G.M., Plane D.A. (eds) Fifty Years of Regional Science. Advances in Spatial Science. Springer, Berlin, Heidelberg, 2004. p. 165-176. https://doi.org/10.1007/978-3-662-07223-3_7

KATZ, B., \& WAGNER, J. The rise of urban innovation districts. Harv. Bus. Rev, 2014.

KAUFMANN, D. Capital cities in interurban competition: Local autonomy, urban governance, and locational policy making. Urban Affairs Review, 2020, Vol. 56, № 4, p. 1168-1205. https://doi. org/10.1177/1078087418809939

KIVI, L. H. Spatial interactions of regional labour markets in Europe. SSRN 3330778, 2019. http:// dx.doi.org/10.2139/ssrn.3330778

KRUGMAN, P. R. Geography and trade. MIT press, 1991.

KWON, K., \& SEO, M. Does the Polycentric Urban Region Contribute to Economic Performance? The Case of Korea. Sustainability, 2018, Vol. 10, N 11, p. 4157. https://doi.org/10.3390/su10114157

LEDUFF, C. Detroit: an American autopsy. Penguin, 2014.

LE GALLO, J., KAMARIANAKIS, Y. The evolution of regional productivity disparities in the European Union from 1975 to 2002: A combination of shift-share and spatial econometrics. Regional Studies, 2011, Vol. 45, № 1, p. 123-139. https://doi.org/10.1080/00343400903234662 
LI, Y., \& MONZUR, T. The spatial structure of employment in the metropolitan region of Tokyo: A scale-view. Urban Geography, 2018, Vol. 39, N² 2, p. 236-262. https://doi.org/10.1080/02723638. 2017.1308182

LOVERIDGE, S., \& SELTING, A. C. A review and comparison of shift-share identities. International Regional Science Review, 1998, vol. 21, no 1, p. 37-58. https://doi.org/10.1177/016001769802100102

MALIZIA, E., FESER, E., RENSKI, H., \& DRUCKER, J. Understanding local economic development. Routledge, 2020.

MARIPANI, J., \& ADIO, E. Concentración social: crecimiento y desempeño del capital humano y social. Encrucijada Americana, 2019, Vol. 11, № 2, p. 19-36.

MASKELL, P. Growth and the territorial configuration of economic activity. Paper presented to DRUID Conference, Aalborg, junio, 2001.

MEIJERS, E.; HOOGERBRUGGE, M., \& CARDOSO, R. Beyond polycentricity: Does stronger integration between cities in polycentric urban regions improve performance? Tijdschrift voor economische en sociale geografie, 2018, Vol. 109, № 1, p. 1-21. https://doi.org/10.1111/tesg.12292

MEIJERS, E., BURGER, M., \& HOOGERBRUGGE, M. Borrowing size in networks of cities: City size, network connectivity and metropolitan functions in Europe. Papers in Regional Science, 2016, Vol. 95, No 1, p. 181-198. https://doi.org/10.1111/pirs.12181

MO, S. W., LEE, K. B., LEE, Y. J., \& PARK, H. G. Analysis of import changes through shift-share, location quotient and BCG techniques: Gwangyang Port in Asia. The Asian Journal of Shipping and Logistics, 2020, Vol. 36, N³, p. 145-156. https://doi.org/10.1016/j.ajsl.2020.01.001

MORETTI, E. The new geography of jobs. Houghton Mifflin Harcourt, 2012.

NAZARA, S., \& HEWINGS, G. JD. Spatial structure and taxonomy of decomposition in shift-share analysis. Growth and Change, 2004, vol. 35, no 4, p. 476-490. https://doi.org/10.1111/j.14682257.2004.00258.x

OECD. Higher Education in Mexico: Labour Market Relevance and Outcomes. Organization for Economic Co-operation and Development, 2019.

O'SULLIVAN, A. Urban Economics. NY, McGraw-Hill, 2018.

ORDÓÑEZ, J., \& GARCÍA, C. Los ránquines de ciudades mundiales: ¿dónde se posiciona Ciudad de México? Investigaciones geográficas, 2019, № 100. https://doi.org/10.14350/rig.60019

PORTER, M. E. Microeconomic foundations of competitiveness-A new agenda for international aid institutions. United Nations Development Programme (UNDP), 2003. 
PSYCHARIS, Y., KALLIORAS, D., \& PANTAZIS, P. Employment changes and regional resilience: an application of tradeadjusted shift-share analysis to the Greek regions. In Resilience, Crisis and Innovation Dynamics. Edward Elgar Publishing, 2018. https://doi.org/10.4337/9781786432193

RAMAJO, J., \& MÁRQUEZ, M. Á. Componentes espaciales en el modelo Shift-Share. Una aplicación al caso de las regiones peninsulares españolas. Estadística española, 2008, Vol. 50, No 168, p. 247-272.

RICHARDSON, H. W. The state of regional economics: a survey article. International regional science review, 1978, Vol. 3, No 1, p. 1-48. https://doi.org/10.1177/016001767800300101

RENDÓN ROJAS, L., ANDRÉS ROSALES, R., \& MEJÍA REYES, P. Shift-Share espacial del empleo manufacturero municipal. Zonas Metropolitanas: Valle de México y Toluca, 2008-2013. Economía, Sociedad y Territorio, 2019, vol. 19, no 59, p. 1213-1242. https://doi.org/10.22136/est20191248

RODRÍGUEZ-POSE, A., \& STORPER, M. Housing, urban growth and inequalities. Urban Studies, 2020, Vol. 57, N², p. 223-248. https://doi.org/10.1177/0042098019859458

SEDATU-CONAPO-INEGI. Delimitación de las zonas metropolitanas de México 2015. Secretaría de Desarrollo Agrario, Territorial y Urbano, Consejo Nacional de Población e Instituto Nacional de Estadística y Geografía, México, 2018.

SHEARMUR, R. Why local development and local innovation are not the same thing: the uneven geographic distribution of innovation-related development. In Handbook on the Geographies of Innovation. Edward Elgar Publishing, 2016. https://doi.org/10.4337/9781784710774.00046

SHEARMUR, R., GARROCHO, C., ÁLVAREZ, J.A., CHÁVEZ, T. Hacia una geografía de las actividades económicas en la Ciudad de México: métodos, conceptos, cultura y subjetividad. En: Garrocho C., y. Buzai G (coords.), Geografía aplicada en Iberoamérica: avances, retos y perspectivas, 2015, p. 431-472.

SINCLAIR-SMITH, K. Polycentric development in the Cape Town city-region: Empirical assessment and consideration of spatial policy implications. Development Southern Africa, 2015, Vol. 32, $\mathrm{N}^{\circ} 2$, p. 131-150. https://doi.org/10.1080/0376835X.2014.984378

SOBRINO, J. Entre mitos y realidades: ciudades mexicanas que concentran clase creativa. Estudios Demográficos y Urbanos, 2016, Vol. 31, № 2, p. 501-522.

STORPER, M. Keys to the city: How economics, institutions, social interaction, and politics shape development. Princeton University Press, 2013.

SWEET, M. N., BULLIVANT, B., \& KANAROGLOU, P. S. Are major canadian city-regions monocentric, polycentric, or dispersed? Urban Geography, 2017, Vol. 38, № 3, p. 445-471. https://doi.org/10.10 80/02723638.2016.1200279 
VALDEZ, R. I. Impacto de la proximidad geográfica en los cambios del empleo manufacturero en México: Análisis Shift-Share espacial. Frontera Norte, 2018, Vol. 30, N 59, p. 155-184. https://doi. org/10.17428/rfn.v30i59.1137

BOUSSAUW, K., DERUDDER, B., \& WITLOX, F. Flemish Diamond or ABC-Axis? The spatial structure of the Belgian metropolitan area. European Planning Studies, 2016, Vol. 24, N 5, p. 974-995. https://doi.org/10.1080/09654313.2016.1139058

VICENTE, J. Economics of clusters. Springer, 2018.

WANG, F., \& NIU, F. Q. Urban Commercial Spatial Structure Optimization in the Metropolitan Area of Beijing: A Microscopic Perspective. Sustainability, 2019, Vol. 11, № 4, p. 1103. https://doi. org/10.3390/su11041103

ZACCOMER, G. P., \& MASON, P. A new spatial shift-share decomposition for the regional growth analysis: a local study of the employment based on Italian Business Statistical Register. Statistical Methods \& Applications, 2011, Vol. 20, N³, p. 329-356. 
